\title{
The Association Between Hypertension and Cognitive Impairment, and the Role of Antihypertensive Medications: A Literature Review
}

Nupur Mishra ${ }^{1}$, Devyani Mohan ${ }^{2}$, Sehrish Fuad ${ }^{1}$, Deepak M. Basavanagowda ${ }^{3}$, Zaid A. Alrashid ${ }^{4}$, Arveen Kaur $^{3}$, Bindu Rathod ${ }^{3}$, Sadia Nosher ${ }^{5}$, Stacey E. Heindl ${ }^{1,6}$

1. Medicine, California Institute of Behavioral Neurosciences \& Psychology, Fairfield, USA 2. Surgery, California Institute of Behavioral Neurosciences \& Psychology, Fairfield, USA 3. Psychiatry and Behavioral Sciences, California Institute of Behavioral Neurosciences \& Psychology, Fairfield, USA 4. Neurology, California Institute of Behavioral Neurosciences \& Psychology, Fairfield, USA 5. Family Medicine, California Institute of Behavioral Neurosciences \& Psychology, Fairfield, USA 6. Medicine, Avalon University School of Medicine, Willemstad, CUW

Corresponding author: Nupur Mishra, mira92@gmail.com

\begin{abstract}
Vascular dementia (VD) is one of the leading causes of dementia, and hypertension is a known risk factor for VD. Hypertension treatment guidelines have previously discussed an optimal blood pressure goal to prevent further cardiovascular complications with long-term management. The treatment of hypertension can prevent stroke, kidney failure, and perhaps prevent cognitive decline as well. We reviewed studies that demonstrated an association between hypertension and cognitive impairment (CI). The role of antihypertensive medications (AHM) in preventing CI was also investigated. This topic is worth exploring as dementia has high healthcare costs and will become prominent as the population in the United States ages. We used the medical subject heading (MeSH) search strategy on Pubmed and reviewed 22 articles. The studies showed that there might be a link between hypertension, AHM, and CI. The studies did not suggest a superiority of any specific AHM class to prevent CI. Further research on optimal hypertension treatment goals to prevent cognitive impairment and dementia is recommended.
\end{abstract}

Received 10/18/2020 Review began 11/04/2020 Review ended 12/02/2020 Published 12/11/2020

() Copyright 2020

Mishra et al. This is an open access article distributed under the terms of the Creative Commons Attribution License CC-BY 4.0., which permits unrestricted use, distribution, and reproduction in any medium, provided the original author and source are credited.
Categories: Cardiology, Family/General Practice, Internal Medicine

Keywords: antihypertensive medications, hypertension, cognitive impairment, angiotensin receptor blockers, thiazide diuretics, ace inhibitors, calcium channel blockers, cognition, dementia, blood pressure

\section{Introduction And Background}

Hypertension guidelines have been a controversial topic in recent years [1]. The 2017 ACC/AHA guideline for the prevention, detection, evaluation, and management of high blood pressure in adults (2017 ACC/AHA guidelines) defined hypertension as any systolic blood pressure (SBP) greater than $130 \mathrm{mmHg}$ ( $\geqslant 130 \mathrm{mmHg}$ ), or diastolic blood pressure (DBP) greater than $80 \mathrm{mmHg}$ ( $\geqslant 80 \mathrm{mmHg}$ ) [2]. These guidelines were changed to incorporate blood pressure (BP) in a spectrum as being normal (SBP $<120$ and DBP $<80 \mathrm{mmHg}$ ), elevated (SBP 120-129 and DBP <80 mmHg), stage one high BP (SBP 130-139 mmHg or DBP 80-89 mmHg), and stage two high BP (SBP $\geqslant 140$ or DBP $\geqslant 90 \mathrm{mmHg}$ ). The $2017 \mathrm{ACC} / \mathrm{AHA}$ guidelines suggested using a treatment goal of $\leqslant 130 / 80 \mathrm{mmHg}$ for all ages, and all comorbidities, with few exceptions [2].

This treatment goal differs from the earlier 2014 Eighth Joint National Committee (JNC-VIII) guidelines for hypertension. Their findings suggested that in ages 60 or greater, a treatment goal of $\leqslant 150 / 90 \mathrm{mmHg}$ should be pursued with pharmacologic treatment. For ages 30 to 59 , they suggested a treatment goal of $\leqslant 140 / 90$ $\mathrm{mmHg}$, with pharmacologic therapy [3]. Apart from referring to age, the JNC-VIII guidelines also established chronic kidney disease (CKD) and diabetes as important comorbidities and separated this patient population from the rest of the general patient population. They specifically mentioned patients with cardiovascular diseases such as stroke as high-risk populations, and the panel members could not reach unanimity for SBP treatment goals in these high-risk groups [3].

In terms of treatment, the 2014 JNC-VIII guidelines suggested diabetes, CKD, and race as a specific patient population group with specific antihypertensive medication guidelines [3]. As such, the treatment algorithm from JNC-VIII guidelines suggested the use of angiotensin-converting enzyme inhibitors (ACEi) or angiotensin receptor blockers (ARB) for hypertensive patients with CKD for all races, thiazides or calcium channel blockers (CCB) for black, non-CKD hypertensive patients, and ACE/ARB, thiazides, or CCB for nonblack, non-CKD hypertensive patients (Figure 1) [3]. 




\section{FIGURE 1: Classification of antihypertensive medications and their} mechanism

$\mathrm{NaCl}$ : sodium chloride, ACE: angiotensin-converting enzyme

The 2017 ACC/AHA guidelines suggested that relative risk reduction for cardiovascular diseases (specifically noted as chronic heart disease, heart failure, and stroke) by using antihypertensive medications (AHM) was fairly similar across the general patient population in terms of age, sex, body mass, CKD, diabetes mellitus (DM), and atrial fibrillation (AF) [2]. They recommended starting pharmacologic treatment for anyone with stage two high BP and anyone with stage one high BP plus a clinical atherosclerotic cardiovascular disease (ASCVD) risk of $\geqslant 10 \%$. For treatment strategy, the study indicated leniency to chose any antihypertensive, except in certain cases such as race or clinical comorbidity. For example, in cases where a far greater benefit was observed, i.e., beta-blockers (BB) after myocardial infarction, diuretics in heart failure patients (Figure $1)$.

These guidelines also highlighted the impact of cardiovascular diseases, such as chronic heart disease, myocardial infarction, stroke [2], and suggested treating BP to prevent the development of cognitive decline (CD) and dementia [2,4-9]. Chronic high blood pressure is also a risk factor for cerebrovascular disease, leading to vascular dementia complications. The prevalence of hypertension seemed to increase with age and was greatest in those more than 75 years of age, with $>79 \%$ of this population being hypertensive [2]. The elderly patient population also reported the greatest cognitive dysfunction, including the spectrum from mild cognitive impairment (MCI) to dementia $[10,11]$

Hypertension might be a contributing risk factor for MCI and dementia and can be targeted for therapy [1214]. The healthcare burden of taking care of elderly patients with dementia is not a small number, and Hurd et al. even placed the cost to be among the highest healthcare expenditure, including heart disease and cancer [15]. Findings from observational studies suggested that treating hypertension in midlife and longterm might prevent $C D$ in the elderly patient population $[2,14,16]$. However, treating hypertension in the elderly population and its contributing effect on cognition is not very clear. The question is, how and why does hypertension affect cognition, and can AHM play a role in preventing cognitive dysfunction?

Cognitive dysfunction covers a spectrum from MCI to dementia [12,17]. The pathophysiology surrounding cognitive dysfunction is varied. Some etiologies of dementia, such as Alzheimer's disease (AD), have novel treatments; however, there is no specific treatment for vascular dementia [12]. Over time, as the United States population ages, it is becoming imperative that we have a greater understanding of treating hypertension in elderly populations. The topic is worth investigating and few studies have also developed study protocols and feasibility trials for studying vascular dementia $[18,19]$. In keeping with these views, the purpose of this review was to investigate studies that dealt with hypertension and AHM and to assess their association with cognitive dysfunction.

\section{Review}

\section{Methods}

Search Strategy

We searched PubMed and MeSH search strategy to find as many as possible relevant articles. The keywords 


\section{Cureus}

included are listed in Tables 1, 2. After manually screening for duplicate and unavailable studies, articles were also screened for their relevance to the topic. A total of 22 articles were identified for discussion.

\begin{tabular}{|c|c|c|c|c|}
\hline PubMed keywords & Database & $\begin{array}{l}\text { Number of } \\
\text { studies }\end{array}$ & $\begin{array}{l}\text { Number of studies with } \\
\text { criteria applied }\end{array}$ & $\begin{array}{l}\text { Number after removing irrelevant, unavailable, and } \\
\text { duplicate studies }\end{array}$ \\
\hline Thiazide + cognitive & PubMed & 138 & 1 & 1 \\
\hline $\begin{array}{l}\text { Calcium channel blocker + } \\
\text { cognitive }\end{array}$ & PubMlied & 1217 & 31 & 6 \\
\hline $\begin{array}{l}\text { Angiotensin receptor blocker } \\
+ \text { cognitive }\end{array}$ & PubMed & 314 & 16 & 1 \\
\hline ACE inhibitors + cognitive & PubMed & 447 & 13 & 0 \\
\hline
\end{tabular}

TABLE 1: PubMed keywords that dealt with specific antihypertensive medications and cognition

ACE: angiotensin-converting enzyme

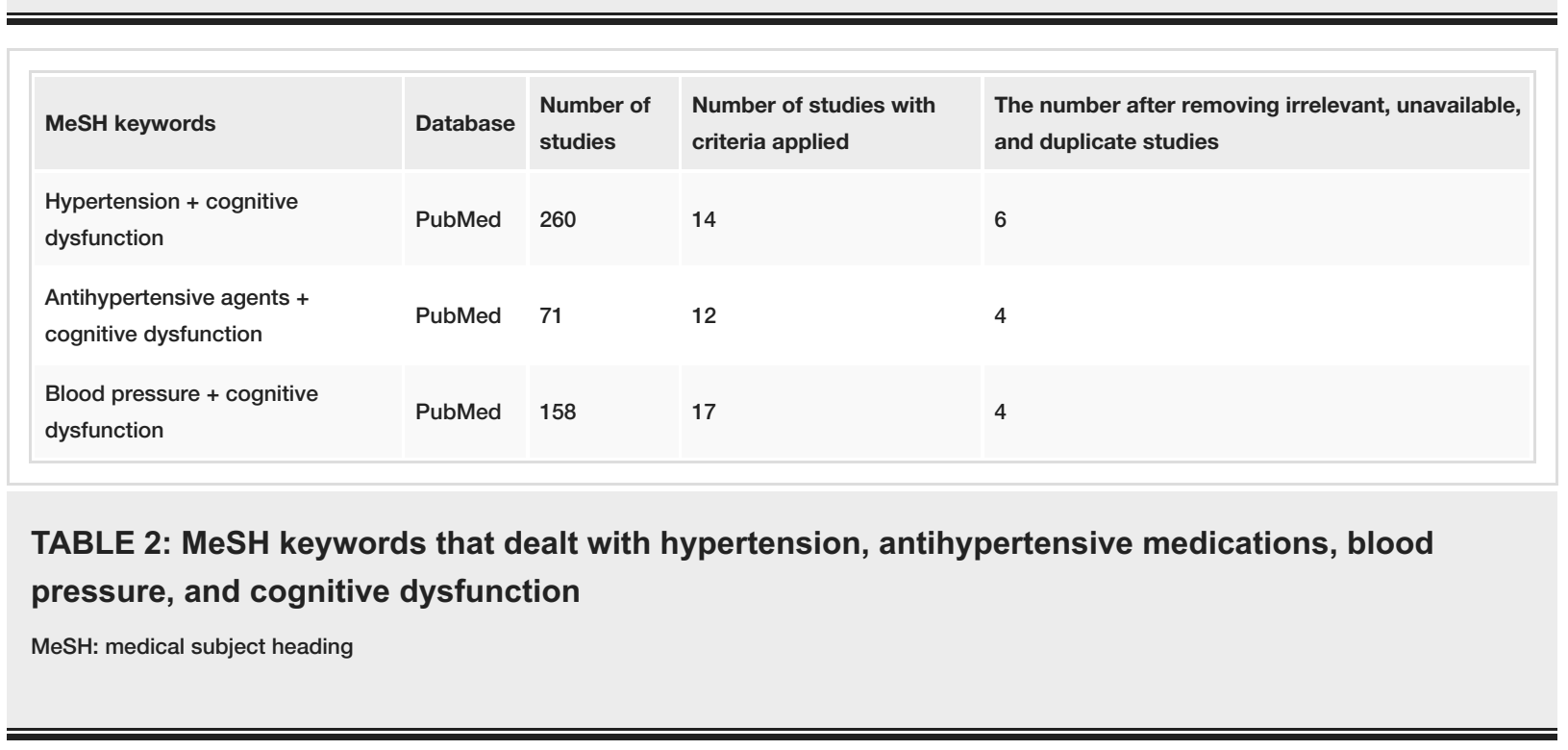

Eligibility Criteria

One author screened the available abstracts using the following inclusion/exclusion criteria. We included studies within the past five years (2015-2020) to review the latest available data. Only papers in the English language were selected. We excluded all studies except clinical trials, meta-analysis, and randomized controlled trials. One animal study was also included. All ages and gender of patients were included. All geographical locations were also included.

\section{Results}

Study Selection and Characteristics

Studies collected from the methods were sorted based on relevance to subtopics and included in Tables 3-6. A total of eleven meta-analyses, four clinical trials, and seven randomized clinical trials (RCT) were included. 


\section{Cureus}

\begin{tabular}{|c|c|c|c|c|}
\hline Authors & Year & Type of study & $\begin{array}{l}\text { Total number } \\
\text { of patients }\end{array}$ & Relevant results and conclusions \\
\hline $\begin{array}{l}\text { Xue et al. } \\
\text { [20] }\end{array}$ & 2019 & Meta-analysis & 6829 & $\begin{array}{l}\text { Not having an APOEe4 allele, or no hypertension, or no history of stroke were } \\
\text { associated with a greater chance to revert from } \mathrm{MCl} \text { to normal cognition }\end{array}$ \\
\hline $\begin{array}{l}\text { Xie et al. } \\
{[21]}\end{array}$ & 2018 & Meta-analysis & 143,095 & $\begin{array}{l}\text { ACEi has significantly reduced all secondary outcomes (all-cause mortality, MI, and } \\
\text { stroke). CCB and diuretics reduced stroke significantly. }\end{array}$ \\
\hline $\begin{array}{l}\text { You et al. } \\
\text { [22] }\end{array}$ & 2017 & $\begin{array}{l}\text { Randomized } \\
\text { clinical trial }\end{array}$ & 2 & $\begin{array}{l}\text { Frequency of } \mathrm{Cl} \text { after Intracerebral hemorrhage may be linked to age, gender, initial } \\
\text { neurological deficit, and high early systolic BP in the first } 24 \text { hours. }\end{array}$ \\
\hline $\begin{array}{l}\text { Sun et al. } \\
\text { [23] }\end{array}$ & 2016 & $\begin{array}{l}\text { Randomized } \\
\text { clinical trial }\end{array}$ & 340 & $\begin{array}{l}\text { Intraoperative use of nicardipine and nitroglycerin along with esmolol may reduce the } \\
\text { incidence of POCD }\end{array}$ \\
\hline $\begin{array}{l}\text { Scharf et } \\
\text { al. [24] }\end{array}$ & 2019 & Clinical trial & 554 & $\begin{array}{l}\text { Age, hypertension, and fasting glucose in males predicted the progression of white } \\
\text { matter hyperintensity. }\end{array}$ \\
\hline $\begin{array}{l}\text { de Heus et } \\
\text { al. [25] }\end{array}$ & 2019 & Clinical trial & 460 & $\begin{array}{l}\text { Greater blood pressure variability might be associated with the progression of } \\
\text { Alzheimer disease }\end{array}$ \\
\hline $\begin{array}{l}\text { Georgakis } \\
\text { et al. [26] }\end{array}$ & 20 & $\begin{array}{l}\text { Meta-analysis, } \\
\text { systematic review }\end{array}$ & 3,25 & $\begin{array}{l}\text { Left ventricular hypertrophy might be independently linked with an increased chance of } \\
\mathrm{Cl}\end{array}$ \\
\hline
\end{tabular}

\section{TABLE 3: Studies that showed a link between cognition and cardiovascular risk factors}

APOEe4: apolipoprotein E4, MCl: mild cognitive impairment, ACEi: angiotensin-converting enzyme inhibitor, MI: myocardial infarction, CCB: calcium channel blockers, Cl: cognitive impairment, BP: blood pressure, POCD: postoperative cognitive decline

\begin{tabular}{|c|c|c|c|c|}
\hline Authors & Year & Type of study & $\begin{array}{l}\text { Total } \\
\text { number of } \\
\text { patients }\end{array}$ & Relevant results and conclusions \\
\hline Parsons et al. [27] & 2016 & Meta-analysis & 57,049 & $\begin{array}{l}\text { Use of antihypertensive medications significantly lowered the risk of } \\
\text { stroke, but not dementia or cognitive decline }\end{array}$ \\
\hline Hughes et al. [28] & 2020 & $\begin{array}{l}\text { Meta- } \\
\text { analysis, } \\
\text { systematic } \\
\text { review }\end{array}$ & 96,158 & $\begin{array}{l}\text { Use of antihypertensive medications significantly lowered the risk of } \\
\text { dementia or } \mathrm{Cl} \text { when compared to control }\end{array}$ \\
\hline Xu et al. [29] & 2017 & Meta-analysis & 30,895 & $\begin{array}{l}\text { Use of antihypertensive medications was associated with reduced risk of } \\
\text { dementia }\end{array}$ \\
\hline $\begin{array}{l}\text { SPRINT MIND Investigators for } \\
\text { the SPRINT Research Group et } \\
\text { al. [12] }\end{array}$ & 2019 & $\begin{array}{l}\text { Randomized } \\
\text { clinical trial }\end{array}$ & 9,361 & $\begin{array}{l}\text { Treatment of SBP goal to less than } 120 \mathrm{mmHg} \text { did not improve the risk of } \\
\text { dementia than the SBP goal to less than } 140 \mathrm{mmHg} \text {, but it did improve } \\
\text { the risk of } \mathrm{MCl} \text {. }\end{array}$ \\
\hline Vazirinejad et al. [30] & 2019 & Clinical trial & 248 & $\begin{array}{l}\text { Use of antihypertensive medications in ages } 40 \text { years or greater showed } \\
\text { an improved level of cognition performance }\end{array}$ \\
\hline Moonen et al. [31] & 2015 & $\begin{array}{l}\text { Randomized } \\
\text { clinical trial }\end{array}$ & 385 & $\begin{array}{l}\text { Stopping antihypertensive medications in elderly patients with } \mathrm{MCl} \text { did } \\
\text { not improve cognitive, psychological, or daily functioning }\end{array}$ \\
\hline
\end{tabular}

TABLE 4: Studies that involved the use of nonspecific antihypertensive medications and cognition

Cl: cognitive impairment, SBP: systolic blood pressure, $\mathrm{MCl}$ : mild cognitive impairment 


\section{Cureus}

\begin{tabular}{|c|c|c|c|c|}
\hline Authors & Year & Type of study & $\begin{array}{l}\text { Total number of } \\
\text { cases }\end{array}$ & Relevant results and conclusions \\
\hline \multicolumn{5}{|l|}{ DIURETICS } \\
\hline $\begin{array}{l}\text { Tully et al. } \\
\text { [32] }\end{array}$ & 2016 & $\begin{array}{l}\text { Meta-analysis, systematic } \\
\text { review }\end{array}$ & 52,599 & $\begin{array}{l}\text { The use of diuretic antihypertensive medications might reduce the risk } \\
\text { of dementia }\end{array}$ \\
\hline \multicolumn{5}{|c|}{ CALCIUM CHANNEL BLOCKERS } \\
\hline $\begin{array}{l}\text { Lawlor et al. } \\
\text { [33] }\end{array}$ & 2018 & Clinical trial & 511 & Nilvadipine might not be useful in older aged patients with $A D$ \\
\hline $\begin{array}{l}\text { de Jong et } \\
\text { al. [34] }\end{array}$ & 2019 & Randomized clinical trial & 58 & $\begin{array}{l}\text { Nilvadipine increased CBF in the hippocampus and has positive } \\
\text { cerebrovascular effects in AD. }\end{array}$ \\
\hline \multicolumn{5}{|c|}{ ANGIOTENSIN II RECEPTOR BLOCKERS } \\
\hline $\begin{array}{l}\text { Ahmed et al. } \\
\text { [35] }\end{array}$ & 2018 & $\begin{array}{l}\text { Randomized clinical trial, } \\
\text { Animal study }\end{array}$ & 41 rats & $\begin{array}{l}\text { RAS targeting AHM use after stroke helped preserve cognitive function } \\
\text { in hypertensive rats }\end{array}$ \\
\hline
\end{tabular}

\section{TABLE 5: Studies that looked at the association between specific antihypertensive medications and cognition}

CBF: cerebral blood flow, AD: Alzheimer's disease, RAS: renin-angiotensin system, AHM: antihypertensive medications

Note: One animal study included [35].

\begin{tabular}{|c|c|c|c|c|}
\hline Authors & Year & $\begin{array}{l}\text { Type of } \\
\text { study }\end{array}$ & $\begin{array}{l}\text { Total } \\
\text { number of } \\
\text { patients }\end{array}$ & Relevant results and conclusions \\
\hline $\begin{array}{l}\text { van } \\
\text { Middelaar et } \\
\text { al [36]. }\end{array}$ & 2017 & $\begin{array}{l}\text { Randomized } \\
\text { clinical trial }\end{array}$ & 3526 & $\begin{array}{l}\text { Both uses of CCB and ARB are independently associated with a decreased risk of } \\
\text { dementia in older people. }\end{array}$ \\
\hline $\begin{array}{l}\text { Zhuang et al. } \\
\text { [37] }\end{array}$ & 2016 & $\begin{array}{l}\text { Meta- } \\
\text { analysis }\end{array}$ & 54,678 & RAS targeting AHM, specifically ACEi, might reduce the incidence of $\mathrm{VCl}$ and VD. \\
\hline $\begin{array}{l}\text { Zhuang et al. } \\
\text { [38] }\end{array}$ & 2016 & $\begin{array}{l}\text { Meta- } \\
\text { analysis }\end{array}$ & $1,268,156$ & $\begin{array}{l}\text { RAS targeting AHM medications might reduce the incidence of dementia. cACEi might } \\
\text { prevent cognitive decline. }\end{array}$ \\
\hline $\begin{array}{l}\text { Zhuang et al. } \\
\text { [39] }\end{array}$ & 2016 & $\begin{array}{l}\text { Meta- } \\
\text { analysis }\end{array}$ & 887,205 & $\begin{array}{l}\text { RAS targeting AHM medications might prevent AD. ARB might reduce the incidence of } \\
\text { cognitive impairment of aging. }\end{array}$ \\
\hline $\begin{array}{l}\text { Peters et al. } \\
{[40]}\end{array}$ & 2020 & $\begin{array}{l}\text { Meta- } \\
\text { analysis }\end{array}$ & 56,866 & $\begin{array}{l}\text { Patient aged }>65 \text { years: only diuretics showed possible benefit in some analysis Patients } \\
\text { aged } 65 \text { years: limited data Findings allow clinical freedom to select AHM }\end{array}$ \\
\hline
\end{tabular}

\section{TABLE 6: Studies that dealt with comparisons of various antihypertensive medications}

CCB: calcium channel blockers, ARB: angiotensin II receptor blockers, RAS: renin-angiotensin system, AHM: antihypertensive medications, ACEi: angiotensin-converting enzyme inhibitors, VCl: vascular cognitive impairment, VD: vascular dementia, CACEi: centrally acting angiotensinconverting enzyme inhibitors, AD: Alzheimer's disease, ARB: angiotensin receptor blockers

\section{Discussion}

Cognition and Cardiovascular Risk Factors

One way to ascertain a link between cognitive dysfunction and hypertension can be to study the risk factors of cognitive impairment (CI) (Table 3). Xue et al. looked for factors that could predict the chance of reversion from MCI to normal cognition (NC) [20]. They looked at a total of 17 studies and performed a meta-analysis accordingly. The analysis showed that of the five articles related to the APOEe4 gene, the APOEe4 allele's absence had an association with reversion from MCI to NC. A similar trend was noticed for having no hypertension, no stroke, which led to a greater chance of reversion [20]. This might suggest that 
dementia unrelated to cardiovascular causes or Alzheimer's disease has a greater chance of recovery. Conversely, hypertension might be a risk factor and a modifiable one at that.

However, the authors admitted limitations to the studies, including variability in study settings and a low number of studies included in the meta-analysis. The study could not stratify based on etiology, and their meta-analysis may have included dementia due to overlapping etiologies [20]. This is a relevant finding, especially when looking at the relationship between AHM and stroke. Xie et al. suggested that AHM can prevent strokes, and preventing strokes can help prevent cognitive dysfunction. They conducted a metaanalysis of 27 RCTs, including hypertensive patients, but not heart failure patients. Their findings showed that ACEi reduced all secondary outcomes, i.e., all-cause mortality, MI, and stroke and that CCB and diuretics significantly decreased the risk of stroke. Since stroke is a risk factor for CI, reducing its risk may help prevent cognitive dysfunction [20,21].

CI, due to hypertension, might not just be limited to a chronic cause. You et al. studied CI in intracerebral hemorrhagic (ICH) patients [22]. They suggested that the systolic blood pressure elevation in the first 24 hours after ICH might be linked to CI. Sun et al. also looked at an acute rise in blood pressure [23]. They conducted an RCT that studied the effect of nicardipine (CCB), nitroglycerin, esmolol (BB), in preventing postoperative cognitive dysfunction (POCD) in elderly patients who underwent surgery and anesthesia, and the incidence of POCD. They found that the patients who received either nicardipine alone or in combination with esmolol had a far lesser incidence of POCD than those that did not receive these interventions. They also specifically mentioned that the absence of ICH complications in all groups, suggesting that POCD may occur independently of complications [23].

The question now arises, how could hypertension, whether acute or chronic, affect cognition? Scharf et al. suggest that hypertension may be asserting its effects by creating changes on a neuronal level [24]. They studied white matter hyperintensity (WMH) via MRI imaging. In their study, they found that WMH, i.e., white matter lesions, were strongly associated with hypertension [24]. Interestingly, they also mentioned that measuring brachial blood pressure might not accurately reflect the effect of atherosclerotic aortic pressure on brain vasculature.

De Heus et al. suggested that fluctuations in BP or blood pressure variability (BPV) could also play a role in developing cognitive disorders (Table 3) [25]. They specifically looked at patients with Alzheimer's disease and found that patients with greater visit-to-visit blood pressure variability had greater CD during the 1.0 and 1.5 years follow up. The authors suggested that a possible cause of Alzheimer's disease in patients with high BPV might involve an impaired clearing of Amyloid $\beta$ plaques and loss of neuronal function due to damage to cerebral microcirculation from the high blood flow pulsatility $[25,41]$. They further suggested that this was mainly associated with diastolic BPV as it was linked to a sympathetic drive or endothelial dysfunction. They also suggested that systolic BPV was linked to arterial stiffness $[25,42,43]$. This can warrant greater research, especially in elderly hypertensive patients, as arterial stiffness increases with age and might be more prevalent in the elderly population.

Another way of looking for a link between hypertension and cognition can be to study the effects of chronic hypertension. Georgakis et al. studied the association of left ventricular hypertrophy (LVH) with CI (Table 3) [26]. The results showed an increased CI risk in patients with LVH in both hypertensive and normal blood pressure patients. The finding was evaluated using electrocardiogram and transthoracic echocardiogram. The authors suggested that the findings could not differentiate between CI that accompanies dementia, Alzheimer's disease, and vascular diseases [26]. Thus, they recommended further research differentiating between these pathologies.

Antihypertensive Medications and Cognition

Many studies have actively looked for a potential link between AHM and cognition; some recent studies have been listed (Table 4). Parsons et al. conducted a meta-analysis and found that AHM significantly reduced stroke [27]. However, they did not have a significant impact on reducing dementia or CD. The authors mentioned that the average follow-up for the studies they included was about 3.1 to 3.5 years. Therefore, they may need to include or conduct studies with a longer follow-up to show the impact on dementia and CD [27]. Hughes et al. did a meta-analysis of only RCTs, and their findings suggested that treating hypertension might decrease dementia and CI incidence [28]. They had a slightly greater duration of follow up, which was reported to be 4.1 years. However, they do note caution, as some of their confidence intervals included one [28].

Similarly, Xu et al. also investigated the AHM role, CD, and dementia [29]. They looked at 10 prospective cohort studies and performed a meta-analysis to look for outcomes such as dementia, AD, CI, and CD. No link was seen between $\mathrm{AHM}$ and $\mathrm{AD}, \mathrm{CI}$, or $\mathrm{CD}$, but an improvement in the incidence of dementia was seen. This was an interesting finding, and the authors suggested that it might have to do with the type of studies used in the meta-analysis. They mentioned that some of their included studies had inconsistent results [29].

Once it can be established that AHM might help prevent CI, it becomes crucial to understand what the 
treatment goal should be, and at what age can the AHM exert their greatest effect. SPRINT MIND Investigators for the SPRINT Research Group et al. conducted a study looking at intensive versus standard blood pressure control and its effect on dementia incidence [12]. They randomly assigned the control group with a blood pressure treatment goal of $120 \mathrm{mmHg}$ and the treatment group with a blood pressure treatment goal of $140 \mathrm{mmHg}$. During follow-up, participants completed cognitive assessments to assess their cognitive status [12].

Results showed that the intensive blood pressure control treatment group had a significantly lower rate of MCI or probable dementia than the control group. The authors admitted that MCI was not the primary outcome of the trial. Though there is a link between MCI and dementia, MCI may also revert to NC. As such, the authors could not conclude whether an SBP goal of less than $120 \mathrm{mmHg}$ is better than a goal of less than $140 \mathrm{mmHg}$ to prevent the risk of dementia [12]. This remains to be further researched. This topic is worth investigating, as an optimal treatment goal could lead to a greater reduction in CI incidence.

As mentioned before, there is an ongoing conversation about what treatment goals should be utilized in elderly hypertensive patients [2,3]. Vazirinejad et al. conducted a clinical trial with 248 participants and measured mini-mental state examination (MMSE) before and after patients underwent hypertension treatment for three months (Table 4) [30]. Their findings showed that the use of AHM in ages greater than 40 significantly improved their cognition performance compared to in ages less than 40 [30]. This showed the importance of treating hypertension optimally, even in the elderly population, as they stand to benefit significantly.

A study done by Moonen et al. allowed us to see a different approach to investigation, as it gave us a view of what might happen to a patient's cognition when AHM are discontinued (Table 4) [31]. Interestingly, low blood pressure in elderly patients is also associated with CD [31,44,14]. When Moonen et al. stopped AHM in the intervention group, they found that the intervention groups increased BP compared to the control group. However, there was no improvement in their cognition. This showed that, on the one hand, the increasing BP did not improve cognition; however, it also didn't worsen it. The authors also mentioned that they had a short follow-up. They could not assess the long-term effect of discontinuing AHM in elderly hypertensive patients [31]. More longitudinal research can be done to explore optimal treatment goals in this patient population.

Specific Antihypertensive Medication Classes and Cognition

Several papers studied individual antihypertensive classes or medications and their effects on cognition (Table 5). Tully et al. point out diuretics as the main drug of use for elderly hypertension patients $[32,45]$. They did a meta-analysis, which included both RCTs and observational studies and showed that diuretics reduced dementia and $\mathrm{AD}$ risk. However, the authors noted the lack of studies done assessing the benefits of diuretics despite being a commonly used AHM. Interestingly, they also stratified the risk reduction by type and mention a reduction of dementia risk by $6 \%$ in thiazides, $14 \%$ in loop, and $30 \%$ in potassium-sparing diuretics [32].

Lawlor et al. and de Jong et al. conducted randomized clinical trials involving Nilvadipine, a dihydropyridine CCB $[33,34]$. Nilvadipine has previously been shown to lower amyloid- $\beta$ in animal studies [33]. Lawlor et al. looked at Alzheimer's disease patients and conducted an 18-month RCT by administering nilvadipine in participants with diagnosed mild to moderate stage AD [33]. They excluded anyone with established dementia from other causes. However, they suggested that they could not exclude all other etiologies, as they did not check for brain amyloid biomarkers. The outcome was assessed using the AD assessment scale cognitive subscale-12 (ADAS-Cog12), clinical dementia rating scale sum of boxes (CDR-sb), and disability assessment for dementia (DAD) measurement scales [33].

Their findings showed that nilvadipine had no statistically significant benefit. It can be argued that AD's pathophysiology is different from vascular dementia and stroke; therefore, this finding may show the benefit of CCB is not generalizable to all pathologies of dementia. The authors mentioned a drop of $5 \mathrm{mmHg}$ median in systolic BP during the treatment, which can favor this argument. The authors also mention that if perhaps cerebral hypoperfusion worsened amyloid deposition, early-stage interventions in AD patients with cerebral blood flow (CBF) altering medications can help prevent dementia in $\mathrm{AD}$ patients too [33], which has also been discussed elsewhere $[25,41]$.

De Jong et al. also studied the effect of nilvadipine in mild to moderate AD patients [34]. They specifically studied whether a six-month treatment duration would bring out any CBF changes by using a special imaging technique, magnetic resonance arterial spin labeling, or ASL, to look at specific brain regions. Their findings showed that nilvadipine therapy led to greater cerebral blood flow in the bilateral hippocampal area. Global and posterior cingulate cortex blood flow did not change [34]. They mentioned that nilvadipine had around $10 \mathrm{mmHg}$ drop in SBP and that global and regional CBF was stable despite this. They suggested that the increased $\mathrm{CBF}$ in the hippocampus was a result of the BP-lowering mechanism. Hypertension may be causing microvascular pathology in $\mathrm{AD}$ patients, which was relieved by the use of AHM. However, a short follow-up duration was noted, as well, no measurements on the structural brain and cognitive measure 
could be done [34].

Ahmed et al. studied $\mathrm{CI}$ in the setting of experimental stroke, and specifically looked at the benefit of the renin-angiotensin system (RAS) targeting AHM can provide [35]. They conducted an animal study involving spontaneously hypertensive rats (SHRs) and induced a temporary 60-min stroke experimentally in the middle cerebral artery. After the reperfusion, they treated the SHRs with candesartan, compound 21, or saline. After seven days, some of the saline group received treatment as well [35]. CI was measured using a combination of sensorimotor/neurobehavioral/cognitive-function tests, histopathology, amyloid- $\beta$, etc.

Their findings suggested that SHRs given candesartan had less CI incidence after induced stroke versus SHRs given compound 21 or saline [35]. They further recommended the use of compound 21, an agonist of angiotensin II type two receptors, an experimental compound used for in-vitro and in-vivo studies with rats, to possibly decrease the incidence of CI. They found that CI could be prevented even if the treatment was delayed for seven days, suggesting the importance of treating BP effectively after stroke to prevent CI [35]. These few studies show that all classes of antihypertensive medications are associated with a reduced risk of cognitive impairment. However, the effect may be due to AHM in general and not a specific AHM class.

\section{Comparing Antihypertensive Medications Classes}

Though many AHM classes have individually shown to decrease the risk of dementia, $\mathrm{CI}$ or $\mathrm{CD}$, there are a few studies done that have compared the risk reduction of dementia across classes of AHM (Table 6). van Middelar et al. conducted an RCT with 3,526 participants, with a mean age of 74.4 years, and out of which 1,951 were hypertensive [36]. They looked at the incidence of all-cause dementia, diagnosed using criteria from the Diagnostic and Statistical Manual of Mental Disorders, Fourth Edition (DSM-IV), and used MMSE for evaluation. They had six to eight years follow-up and found that of the patients using AHM at baseline and onwards, 136 participants developed dementia. The authors noted that CCB and ARB had an independent effect on reducing the risk of dementia. They also suggested that this association was strongest in CCB, especially in patients without a history of cardiovascular disease or uncontrolled hypertension. Perhaps this could be linked to the presence of fewer vascular lesions in these patients [36]. This also points towards the importance of starting and maintaining an optimal antihypertensive medication regimen to prevent $\mathrm{CD}$.

Zhuang et al. conducted a series of meta-analyses to look at vascular dementia and AD [37-39]. They believed that RAS targeting AHM may have a greater benefit than others in reducing CD and dementia [39,46,47]. Their findings suggested that RAS blocking AHM might reduce the incidence of dementia [38], vascular cognitive impairment (VCI), and vascular dementia (VD) [37], as well as AD [39]. They also specifically mentioned that ACEi might reduce the incidence of VCI and VD [37]; centrally acting ACEi might prevent CD [38], and ARB might reduce the incidence of cognitive impairment of aging [39]. These different metaanalyses can help us better understand the various presentation of VCI and the etiology and pathophysiology of dementia and the role AHM can play to prevent CI (Figure 2) [37-39]. Blood pressure has been linked to Alzheimer's disease [25]. Individuals with Alzheimer's disease commonly exhibit vascular damage features combined with $\beta$-amyloid and tau neuropathology [12,48-50]. These meta-analyses also showed that apart from CCB [33,34], the RAS targeting AHM class might also affect neuropathology.

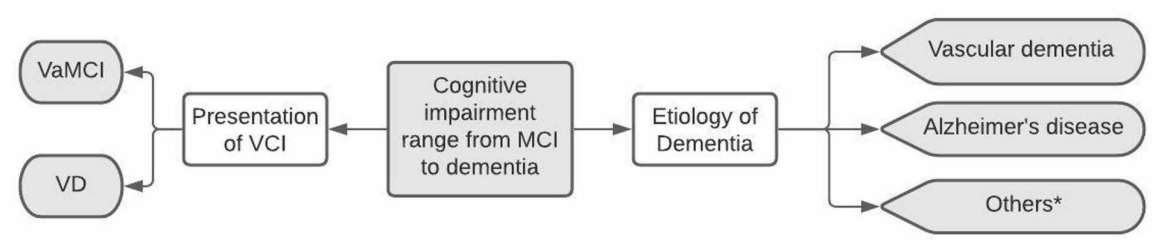

\section{FIGURE 2: Overview of different etiologies of dementia and the range of presentation of vascular cognitive impairment}

${ }^{*}$ Other causes include frontotemporal dementia, Lewy body dementia, pseudodementia, HIV-associated dementia, etc.

MCl: mild cognitive impairment, VCl: vascular cognitive impairment, VaMCl: vascular mild cognitive impairment, VD: vascular dementia

Peters et al. recently conducted a meta-analysis comparing various classes of AHM [40]. Their study was different because it measured incident CD using a reliable change index (RCI), which standardized a decline in cognition across various tests. Their findings suggested that the use of diuretics in ages greater than 65 led to reduced dementia and CD risk. However, the effect was non-consistent, and they suggested that there 


\section{Cureus}

could be clinical freedom to choose any antihypertensive class for the treatment of hypertension [40]. These findings also pointed towards conducting studies that more closely study diuretics and their effect on cognition $[32,40]$.

Future Approach

Peters et al. have a different approach by using RCI as most of the studies conducted incorporated different modes of measurements (Table 7). It could be useful to have a standard measurement across studies when investigating changes in cognition. This can be challenging given the variability; however, having various baseline measurements in control groups can help. This will further prevent bias and will lead to more meaningful results.

\begin{tabular}{|c|c|c|c|c|c|}
\hline Authors & $\begin{array}{l}\text { Type of studies } \\
\text { included }\end{array}$ & $\begin{array}{l}\text { Mean, median, } \\
\text { minimum, or range } \\
\text { of age of the patient } \\
\text { population (years) }\end{array}$ & $\begin{array}{l}\text { Mean, median, } \\
\text { minimum, or } \\
\text { range of follow- } \\
\text { up time (years) }\end{array}$ & $\begin{array}{l}\text { Mode of measurement used to assess } \\
\text { cognition }\end{array}$ & $\begin{array}{l}\text { Etiology present } \\
\text { in the patient } \\
\text { population }\end{array}$ \\
\hline $\begin{array}{l}\text { Parsons } \\
\text { et al. } \\
\text { [27] }\end{array}$ & 14 RCT & $>65$ & $>2$ & $\begin{array}{l}\text { Diagnostic criteria for dementia, changes in } \\
\text { cognitive test scores (e.g. MMSE) }\end{array}$ & $\begin{array}{l}\text { Stroke, TIA, } \\
\text { dementia, CD }\end{array}$ \\
\hline $\begin{array}{l}\text { Hughes } \\
\text { et al. } \\
\text { [28] }\end{array}$ & $14 \mathrm{RCT}$ & Mean 69 & Mean 4.1 & $\begin{array}{l}\text { Incidence of dementia (DSM-3R, DSM-4, ICD-10, } \\
\text { investigator reported, specialist confirmed, } \\
\text { changes in cognitive test scores (e.g. MMSE) }\end{array}$ & Dementia \\
\hline $\begin{array}{l}\text { Xu et al. } \\
{[29]}\end{array}$ & $\begin{array}{l}10 \text { prospective } \\
\text { cohort study }\end{array}$ & 68.7 to 83.0 & $2.2-32.0$ & Incidence of dementia, AD, Cl, CD & $\begin{array}{l}\text { Dementia, } A D, C I \\
\text { CD (PMH of } \\
\text { stroke, DM, CVD) }\end{array}$ \\
\hline $\begin{array}{l}\text { Tully et } \\
\text { al. [32] }\end{array}$ & $\begin{array}{l}15 \text { prospective } \\
\text { studies (incl. RCT, } \\
\text { longitudinal cohort, } \\
\text { database registry) }\end{array}$ & Median 76.1 & Median 6.1 & $\begin{array}{l}\text { Incident dementia and probable dementia, } \\
\text { probable AD (standardized criteria, and the } \\
\text { diagnosis made by clinician including DSM-3R, } \\
\text { DSM-4, NINCDS-ADRDA, NINDS-AIREN) }\end{array}$ & $\begin{array}{l}\text { Dementia } \\
\text { (included AD, VD, } \\
\text { mixed dementia, } \\
\text { unspecified, and } \\
\text { other) }\end{array}$ \\
\hline $\begin{array}{l}\text { Zhuang } \\
\text { et al. } \\
{[37]}\end{array}$ & $\begin{array}{l}5 \text { studies ( } 3 \text { RCTs, } \\
2 \text { case-control) }\end{array}$ & - & - & $\begin{array}{l}\text { Incidence of VCI (DSM-4, MMSE } \leq 24 \text {, MMSE } \\
\leq 23 \text {, OXMIS, records) }\end{array}$ & $\begin{array}{l}\text { VD, probable VD, } \\
\mathrm{Cl}\end{array}$ \\
\hline $\begin{array}{l}\text { Zhuang } \\
\text { et al. } \\
\text { [38] }\end{array}$ & $\begin{array}{l}10 \text { studies ( } 5 \text { RCT, } \\
3 \text { cohorts, } 2 \text { case- } \\
\text { control) }\end{array}$ & - & - & $\begin{array}{l}\text { Incidence of dementia, CD (various studies } \\
\text { included DSM-4, MMSE, ICD- } 9 \text {, ICD-10, } \\
\text { NINCDS-ADRDA, OXMIS as criteria) }\end{array}$ & $\begin{array}{l}\text { Dementia (PMH } \\
\text { incl. DM, stroke) }\end{array}$ \\
\hline $\begin{array}{l}\text { Zhuang } \\
\text { et al. } \\
\text { [39] }\end{array}$ & $\begin{array}{l}10 \text { studies }(1 \mathrm{RCT} \text {, } \\
7 \text { cohorts, } 2 \text { case- } \\
\text { control) }\end{array}$ & - & $3-8$ & $\begin{array}{l}\text { DSM-4, MMSE, ADL, ICD-9, ICD-10, NINCDS- } \\
\text { ADRDA, OXMIS, CASI<74 as outcome measures }\end{array}$ & $\begin{array}{l}\text { AD, probable or } \\
\text { possible } \mathrm{AD}, \mathrm{Cl} \text {, } \\
\mathrm{MCl}\end{array}$ \\
\hline $\begin{array}{l}\text { Peters } \\
\text { et al. } \\
{[40]}\end{array}$ & $\begin{array}{l}27 \text { studies ( } 21 \\
\text { observational } \\
\text { cohort studies, } 2 \\
\text { clinical trials, } 4 \\
\text { RCT) }\end{array}$ & $\begin{array}{l}57.0-93.0 \text { (majority in } \\
\text { 70-79). Data was } \\
\text { stratified by age, } \\
\text { midlife ( } \leq 65) \text { or late } \\
(>65)\end{array}$ & $\geq 1$ & $\begin{array}{l}\text { CD assessed using MMSE screening test. } \\
\text { Incident dementia (DSM-3R, DSM-4, CDR score } \\
\geq 1 \text {, international diagnostic evaluation, } \\
\text { neuropsychological testing) }\end{array}$ & $\begin{array}{l}\text { Dementia, CD. (No } \\
\text { prevalent } \\
\text { dementia at } \\
\text { baseline) }\end{array}$ \\
\hline
\end{tabular}

\section{TABLE 7: Available characteristics of meta-analyses that studied the association between antihypertensive medications and cognition}

RCT: randomized clinical trials, MMSE: mini-mental status examination, TIA: transient ischemic attack, CD: cognitive decline, AD: Alzheimer's disease, Cl: cognitive impairment, PMH: past medical history, DM: diabetes mellitus, CVD: cardiovascular diseases, VD: vascular dementia, DSM3R: Diagnostic and Statistical Manual of Mental Disorders Third Edition Revised, DSM-4: Diagnostic and Statistical Manual of Mental Disorders Fourth Edition, NINCDS-ADRDA: National Institute of Neurological and Communicative Disorders and Stroke and the Alzheimer's Disease and Related Disorders Association, NINDS-AIREN: International Workshop of the National Institute of Neurological Disorders and Stroke (NINDS) and the Association Internationale pour la Recherche et l'Enseignement en Neurosciences (AIREN), ICD-9: International Classification of Diseases 9, ICD-10: International Classification of Diseases 10, OXMIS: Oxford Medical Information System, ADL: activities of daily living, CASI: Cognitive Abilities Screening Instrument, MCI: mild cognitive impairment, CDR: Clinical Dementia Rating scale, VCl: vascular cognitive impairment

Note: Data were collected by the specific mentions the studies made, and not by evaluating the studies included in the meta-analyses. 
Another difference in the studies was the pathophysiology of dementia itself. Some studies specifically included patients with a particular etiology of dementia, whereas others were more lenient. From some of the findings, it seems that AHM could affect outcomes in stroke or vascular dementia and other pathologies. This might also help better understand the role of cerebral perfusion and blood pressure in cognitive disorders. However, all these concerns make it difficult to study vascular dementia or cognitive dysfunction in hypertensive patients.

Based on the current studies, it is impossible to say with absolute confidence that one AHM class is more beneficial than others in preventing vascular dementia from chronic hypertension. However, CCB and ARB seem to have shown great benefit. Further research should be geared towards replicating previous clinical studies, creating standard screening measurement scales for elderly hypertensive patients more vulnerable to future cognitive dysfunction, and finding optimal hypertension treatment goals in midlife vs. elderly hypertensive patients. Since dementia or cognitive impairment may develop over time, there is also a need to include or perform studies with a much longer follow up.

\section{Limitations}

The analysis of the most current studies done on hypertension and cognition revealed some limitations. One issue was the difference in the type of studies utilized in meta-analysis. Many meta-analyses differed in whether they included prospective cohort studies and clinical trials (Table 7). Xu et al mentioned this mixture of types of studies involved as a limitation [29]. There is also a dilemma of whether to assess the incidence of dementia and other cognitive pathologies as they present and whether their findings can correlate well with studies that looked at genetic markers or imaging techniques such as fMRI or ASL. This might create smaller pools within the meta-analysis studies and possibly lead to greater bias. Another thing would be to carefully select studies because the type, year, and the number of related publications included during that year might lead to bias. Diuretics AHM especially seemed to lack in the number of studies conducted $[32,40]$.

This was not a systematic review; therefore, the quality of the papers studied cannot be ascertained. However, the inclusion and exclusion criteria only used meta-analysis, RCTs, and other clinical trials to limit bias and possibly assess causation. Not all clinical trials were randomized and may not include control groups. One animal study was also included.

\section{Conclusions}

This review looked at studies that showed how and why hypertension might affect cognition and whether AHM plays a role in preventing cognitive impairment. We included meta-analysis, RCT, and clinical trials. The findings showed that the risk factors that affect cognition include hypertension, stroke, age, BPV, and LVH. The use of AHM was associated with a reduced risk of stroke, dementia, CI to various degrees. Studies showed that AHM might be useful across dementia pathologies such as AD and VD. Many AHM classes were individually associated with reducing the risk of cognitive impairment; however, comparing the AHM class effect on cognition was difficult.

We looked at the limitations of studies that included type, number, or mode of measurement of cognition used in meta-analysis. The studies did not show the superiority of any one AHM class in preventing cognition impairment. It might be more beneficial to further research hypertension treatment goals to prevent cognitive impairment in both acute and chronic high BP. It might be useful to measure BP in-office visits, as well as monitor fluctuations in BP, and assess SBP and DBP individually, to better predict the risk of vascular dementia. This review analyzed the trend of recent studies done in studying AHM and cognition.

\section{Additional Information}

\section{Disclosures}

Conflicts of interest: In compliance with the ICMJE uniform disclosure form, all authors declare the following: Payment/services info: All authors have declared that no financial support was received from any organization for the submitted work. Financial relationships: All authors have declared that they have no financial relationships at present or within the previous three years with any organizations that might have an interest in the submitted work. Other relationships: All authors have declared that there are no other relationships or activities that could appear to have influenced the submitted work.

\section{References}

1. DePalma SM, Himmelfarb CD, MacLaughlin EJ, Taler SJ: Hypertension guideline update: a new guideline for a new era. JAAPA. 2018, 31:16-22. 10.1097/01.JAA.0000533656.93911.38

2. Whelton PK, Carey RM, Aronow WS, et al.: 2017 ACC/AHA/AAPA/ABC/ACPM/AGS/APhA/ASH/ASPC/NMA/PCNA Guideline for the prevention, detection, evaluation, and management of high blood pressure in adults: executive summary: a report of the American college of cardiology/American heart association task force on clinical practice guidelines. Hypertension. 2018, 71:1269-1324. 10.1161/HYP.0000000000000066 
3. James PA, Oparil S, Carter BL, et al.: 2014 evidence-based guideline for the management of high blood pressure in adults: report from the panel members appointed to the Eighth Joint National Committee (JNC 8). JAMA. 2014, 311:507-520. 10.1001/jama.2013.284427

4. Applegate WB, Pressel S, Wittes J, et al.: Impact of the treatment of isolated systolic hypertension on behavioral variables. Results from the systolic hypertension in the elderly program. Arch Intern Med. 1994, 154:2154-2160.

5. Forette F, Seux ML, Staessen JA, et al.: Prevention of dementia in randomised double-blind placebocontrolled Systolic Hypertension in Europe (Syst-Eur) trial. Lancet. 1998, 352:1347-1351. 10.1016/s01406736(98)03086-4

6. Forette F, Seux ML, Staessen JA, et al.: The prevention of dementia with antihypertensive treatment: new evidence from the Systolic Hypertension in Europe (Syst-Eur) study. Arch Intern Med. 2002, 162:2046-2052. 10.1001/archinte.162.18.2046

7. Lithell H, Hansson L, Skoog I, et al.: The study on cognition and prognosis in the elderly (SCOPE): principal results of a randomized double-blind intervention trial. J Hypertens. 2003, 21:875-886. 10.1097/00004872200305000-00011

8. Tzourio C, Anderson C, Chapman N, et al.: Effects of blood pressure lowering with perindopril and indapamide therapy on dementia and cognitive decline in patients with cerebrovascular disease. Arch Intern Med. 2003, 163:1069-1075. 10.1001/archinte.163.9.1069

9. Peters R, Beckett N, Forette F, et al.: Incident dementia and blood pressure lowering in the Hypertension in the Very Elderly Trial cognitive function assessment (HYVET-COG): a double-blind, placebo controlled trial. Lancet Neurol. 2008, 7:683-689. 10.1016/S1474-4422(08)70143-1

10. Roberts R, Knopman DS: Classification and epidemiology of MCI. Clin Geriatr Med. 2013, 29:753-772. 10.1016/j.cger.2013.07.003

11. Gillis C, Mirzaei F, Potashman M, Ikram MA, Maserejian N: The incidence of mild cognitive impairment: a systematic review and data synthesis. Alzheimers Dement (Amst). 2019, 11:248-256. 10.1016/j.dadm.2019.01.004

12. SPRINT MIND Investigators for the SPRINT Research Group, Williamson JD, Pajewski NM, et al.: Effect of intensive vs standard blood pressure control on probable dementia: a randomized clinical trial. JAMA. 2019, 321:553-561. 10.1001/jama.2018.21442

13. Kivipelto M, Helkala EL, Hänninen T, et al.: Midlife vascular risk factors and late-life mild cognitive impairment: a population-based study. Neurology. 2001, 56:1683-1689. 10.1212/wnl.56.12.1683

14. Qiu C, Winblad B, Fratiglioni L: The age-dependent relation of blood pressure to cognitive function and dementia. Lancet Neurol. 2005, 4:487-499. 10.1016/S1474-4422(05)70141-1

15. Hurd MD, Martorell P, Delavande A, et al.: Monetary costs of dementia in the United States . N Engl J Med. 2013, 368:1326-1334. 10.1056/NEJMsa1204629

16. Hughes TM, Sink KM: Hypertension and its role in cognitive function: current evidence and challenges for the future. Am J Hypertens. 2016, 29:149-57. 10.1093/ajh/hpv180

17. Morris JC, Storandt M, Miller JP, et al.: Mild cognitive impairment represents early-stage Alzheimer disease . Arch Neurol. 2001, 58:397-405. 10.1001/archneur.58.3.397

18. Greenan C, Murphy L, Yu LM, et al.: A randomised controlled trial of calcium channel blockade (CCB) with amlodipine for the treatment oF subcortical ischaEmic vasCular demenTia (AFFECT): study protocol. Trials. 2016, 17:324. 10.1186/s13063-016-1449-3

19. Myint PK, Loke YK, Davison W, et al.: Protocol for a feasibility randomised controlled trial of screening and enhanced risk management for vascular event-related decline in memory (SERVED Memory). BMJ Open. 2017, 7:017416.

20. Xue H, Hou P, Li Y, Mao X, Wu L, Liu Y: Factors for predicting reversion from mild cognitive impairment to normal cognition: a meta-analysis. Int J Geriatr Psychiatry. 2019, 34:1361-1368. 10.1002/gps.5159

21. Xie W, Zheng F, Evangelou E, et al.: Blood pressure-lowering drugs and secondary prevention of cardiovascular disease: systematic review and meta-analysis. J Hypertens. 2018, 36:1256-1265. 10.1097/HJH.0000000000001720

22. You S, Wang X, Lindley RI, et al.: Early cognitive impairment after intracerebral hemorrhage in the INTERACT1 study. Cerebrovasc Dis. 2017, 44:320-324. 10.1159/000481443

23. Sun SH, Yang L, Sun DF, Wu Y, Han J, Liu RC, Wang LJ: Effects of vasodilator and esmolol-induced hemodynamic stability on early postoperative cognitive dysfunction in elderly patients: a randomized trial. Afr Health Sci. 2016, 16:1056-1066. 10.4314/ahs.v16i4.23

24. Scharf EL, Graff-Radford J, Przybelski SA, et al.: Cardiometabolic health and longitudinal progression of white matter hyperintensity: the mayo clinic study of aging. Stroke. 2019, 50:3037-3044. 10.1161/STROKEAHA.119.025822

25. de Heus RAA, Olde Rikkert MGM, Tully PJ, Lawlor BA, Claassen JAHR, NILVAD Study Group: Blood pressure variability and progression of clinical Alzheimer disease. Hypertension. 2019, 74:1172-1180. 10.1161/HYPERTENSIONAHA.119.13664

26. Georgakis MK, Synetos A, Mihas C, Karalexi MA, Tousoulis D, Seshadri S, Th Petridou E: Left ventricular hypertrophy in association with cognitive impairment: a systematic review and meta-analysis. Hypertens Res. 2017, 40:696-709. 10.1038/hr.2017.11

27. Parsons C, Murad MH, Andersen S, Mookadam F, Labonte H: The effect of antihypertensive treatment on the incidence of stroke and cognitive decline in the elderly: a meta-analysis. Future Cardiol. 2016, 12:237-248. $10.2217 /$ fca. 15.90

28. Hughes D, Judge C, Murphy R, et al.: Association of blood pressure lowering with incident dementia or cognitive impairment: a systematic review and meta-analysis. JAMA. 2020, 323:1934-1944. 10.1001/jama.2020.4249

29. Xu G, Bai F, Lin X, et al.: Association between antihypertensive drug use and the incidence of cognitive decline and dementia: a meta-analysis of prospective cohort studies. Biomed Res Int. 2017, 2017:4368474. $10.1155 / 2017 / 4368474$

30. Vazirinejad R, Mirmotalebi M, Bageri M, Kounis NG, Koniari I, Lilley JM, Gommnami N: Age-related effect of 
antihypertensive treatment on cognitive performance: is it better preventing dementia in older age?. Am J Alzheimers Dis Other Demen. 2019, 34:486-491. 10.1177/1533317519859197

31. Moonen JE, Foster-Dingley JC, de Ruijter W, et al.: Effect of discontinuation of antihypertensive treatment in elderly people on cognitive functioning--the DANTE study Leiden: a randomized clinical trial. JAMA Intern Med. 2015, 175:1622-1630. 10.1001/jamainternmed.2015.4103

32. Tully PJ, Hanon O, Cosh S, Tzourio C: Diuretic antihypertensive drugs and incident dementia risk: a systematic review, meta-analysis and meta-regression of prospective studies. J Hypertens. 2016, 34:10271035. 10.1097/HJH.0000000000000868

33. Lawlor B, Segurado R, Kennelly S, et al.: Nilvadipine in mild to moderate Alzheimer disease: a randomised controlled trial. PLoS Med. 2018, 15:1002660. 10.1371/journal.pmed.1002660

34. de Jong D, de Heus R, Rijpma A, et al.: Effects of nilvadipine on cerebral blood flow in patients with Alzheimer disease. Hypertension. 2019, 74:413-420. 10.1161/HYPERTENSIONAHA.119.12892

35. Ahmed HA, Ishrat T, Pillai B, et al.: RAS modulation prevents progressive cognitive impairment after experimental stroke: a randomized, blinded preclinical trial. J Neuroinflammation. 2018, 15:229. 10.1186/s12974-018-1262-x

36. van Middelaar T, van Vught LA, Moll van Charante EP, et al.: Lower dementia risk with different classes of antihypertensive medication in older patients. J Hypertens. 2017, 35:2095-2101. 10.1097/HJH.0000000000001411

37. Zhuang S, Li J, Wang X, Wang HF, Zhang WJ, Wang HY, Xing CM: Renin-angiotensin system-targeting antihypertensive drugs and risk of vascular cognitive impairment: a meta-analysis. Neurosci Lett. 2016, 615:1-8. 10.1016/j.neulet.2016.01.011

38. Zhuang S, Wang HF, Li J, Wang HY, Wang X, Xing CM: Renin-angiotensin system blockade use and risks of cognitive decline and dementia: a meta-analysis. Neurosci Lett. 2016, 624:53-61. 10.1016/j.neulet.2016.05.003

39. Zhuang S, Wang HF, Wang X, Li J, Xing CM: The association of renin-angiotensin system blockade use with the risks of cognitive impairment of aging and Alzheimer's disease: a meta-analysis. J Clin Neurosci. 2016, 33:32-38. 10.1016/j.jocn.2016.02.036

40. Peters R, Yasar S, Anderson CS, et al.: Investigation of antihypertensive class, dementia, and cognitive decline: a meta-analysis. Neurology. 2020, 94:267-281. 10.1212/WNL.0000000000008732

41. Gupta A, Iadecola C: Impaired A $\beta$ clearance: a potential link between ath- erosclerosis and alzheimer's disease. Front Aging Neurosci. 2015, 7:115. 10.3389/fnagi.2015.00115

42. Parati G, Stergiou GS, Dolan E, Bilo G: Blood pressure variability: clinical relevance and application . J Clin Hypertens (Greenwich). 2018, 20:1133-1137. 10.1111/jch.13304

43. Bilo G, Parati G: Blood pressure variability and kidney disease: another vicious circle? . J Hypertens. 2018, 36:1019-1021. 10.1097/HJH.000000000001707

44. Kennelly SP, Lawlor BA, Kenny RA: Blood pressure and the risk for dementia: a double edged sword . Ageing Res Rev. 2009, 8:61-70. 10.1016/j.arr.2008.11.001

45. Moser M, Feig PU: Fifty years of thiazide diuretic therapy for hypertension . Arch Intern Med. 2009, 169:1851-1856. 10.1001/archinternmed.2009.342

46. Fournier A, Oprisiu-Fournier R, Serot JM, et al.: Prevention of dementia by antihypertensive drugs: how AT1-receptor-blockers and dihydropyridines better prevent dementia in hypertensive patients than thiazides and ACE- inhibitors. Expert Rev Neurother. 2009, 9:1413-1431. 10.1586/ern.09.89

47. Shah K, Qureshi SU, Johnson M, Parikh N, Schulz PE, Kunik ME: Does use of antihypertensive drugs affect the incidence or progression of dementia? A systematic review. Am J Geriatr Pharmacother. 2009, 7:250261. 10.1016/j.amjopharm.2009.11.001

48. Schneider JA, Arvanitakis Z, Bang W, Bennett DA: Mixed brain pathologies account for most dementia cases in community-dwelling older persons. Neurology. 2007, 69:2197-2204.

10.1212/01.wnl.0000271090.28148.24

49. Haroutunian V, Schnaider-Beeri M, Schmeidler J, et al.: Role of the neuropathology of Alzheimer disease in dementia in the oldest-old. Arch Neurol. 2008, 65:1211-1217. 10.1001/archneur.65.9.1211

50. Savva GM, Wharton SB, Ince PG, et al.: Age, neuropathology, and dementia. N Engl J Med. 2009, 360:23022309. 10.1056/NEJMoa0806142 